\title{
BENEFITS OF THE WALANT TECHNIQUE AGAINST THE COVID-19 PANDEMIC
}

\section{BENEFÍCIOS DA TÉCNICA WALANT EM CIRURGIAS DA MÃO FRENTE A PANDEMIA DA COVID-19}

\author{
Rafael Saleme Alves ${ }^{1,2}$ (), Daniel Alexandre Pereira Consoni ${ }^{1}$ (i), Pedro Henrique Oliveira Fernandes ${ }^{1}$ (1),

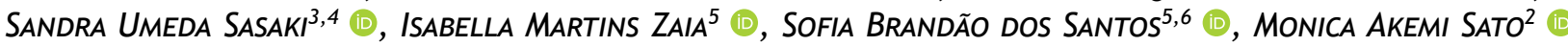

1. Hospital IFOR, São Bernardo do Campo, SP, Brazil.

2. Faculdade de Medicina do ABC, Santo André, SP, Brazil.

3. Hospital Sírio Libanês, São Paulo, SP, Brazil.

4. Universidade de São Paulo, São Paulo, SP, Brazil.

5. Universidade Cidade de São Paulo, São Paulo, SP, Brazil.

6. Faculdade de Ciências Médicas de Santos, Centro Universitário Lusíada, Santos, SP, Brazil.

\section{ABSTRACT}

Objective: Evaluate the experience of private and public health services with the WALANT procedure in the COVID-19 pandemic. Methods: This is a retrospective, multicenter longitudinal study gathering cases of hand surgery subjected to the WALANT technique in the Hospitals Dr. Radamés Nardini and IFOR during the COVID-19 pandemic (August 2020). As a parameter, the verbal numerical rating scale for twenty patients referring to the preoperative, intraoperative and postoperative periods was applied. Results: The patients did not feel any pain during surgery, which showed the efficiency of the anesthetic technique in its purpose. Conclusion: The results indicate the WALANT technique as beneficial when facing the COVID-19 pandemic, as the main differential of the technique is that it is applied by a well-trained orthopedic hand surgeon. Level of Evidence IV, Case Series.

Keywords: Local Anesthesia. Covid-19. Epinephrine. Lidocaine. Hand. Carpal Tunnel Syndrome.

\section{RESUMO}

Objective: Avaliar a experiência dos serviços privado e público de saúde com o procedimento WALANT frente à pandemia COVID-19. Métodos: Trata-se de um estudo longitudinal retrospectivo, multicêntrico, de casos de cirurgia de mão submetidos à técnica WALANT nos hospitais Dr. Radamés Nardini e IFOR, durante a pandemia da COVID-19, em agosto de 2020. Como parâmetro, foi aplicada a Escala Verbal de Dor para 20 pacientes referente ao pré-operatório, intra-operatório e no pós-operatório. Resultados: Os pacientes não sentiram nenhuma dor durante a cirurgia, tendo a técnica anestésica de mostrado eficaz. Conclusão: Pelas análises, foi possivvel considerar segura e benéfica a técnica WALANT diante da pandemia da COVID-19, que apresenta o diferencial de ser aplicada por um cirurgião ortopédico especialista em mão bem treinado. Nível de Evidência IV, Série de Casos.

Descritores: Anestesia Local. Covid-19. Epinefrina. Lidocaína. Mão. Síndrome do Túnel Carpal.

Citation: Alves RS, Consoni DAP, Fernandes PHO, Sasaki SU, Zaia IM, Santos SB, Sato MA. Benefits of the walant technique against the Covid-19 pandemic. Acta Ortop Bras. [online]. 2021;29(5):274-276. Available from URL: http://www.scielo.br/aob.

\section{INTRODUCTION}

The WALANT anesthetic technique (Wide Awake Local Anesthesia no Tourniquet) is an innovation in hand surgery in orthopedics and traumatology services. ${ }^{1}$ The technique is performed by an orthopedic surgeon with the patient wide awake and without tourniquet, using local anesthetic technique and lidocaine with epinephrine, which gives anesthetic and vasoconstrictive effect. This technique brings numerous surgical benefits to patients and hospital health services. Operating the patient in a vigil state brings the advantage of checking in real time the result of the surgery in the intraoperative period, in addition to immediately correct any surgical failure. Even with vasoconstrictive effect, the use of epinephrine in extremities proves to be a possible and safe procedure..$^{1-3}$

Besides the primary effect of this anesthetic technique, it brings several benefits for the patient. First, it dispenses with preoperative examinations, ${ }^{2}$ being convenient for patients with medical comorbidities, ${ }^{2,4}$ because it does not require suspension of continuous-use medications, as well as fasting is not necessary, ${ }^{4}$ which makes it an excellent benefit for diabetic patients, avoiding hypoglycemia. Second, it prevents exposure of the patient to anesthetic and sedation effects, reducing complications and adverse effect.

Third, with the patient in a vigil state, it is possible to verify bone stability in the case of the osteosynthesis procedure, as well as the integrity of the suture in the tenorrhaphies, thus evaluating the

All authors declare no potential conflict of interest related to this article.

The study was conducted at the Hospital IFOR and Hospital de Clínicas Dr. Radamés Nardini.

Correspondence: Rafael Saleme Alves. Av. Lauro Gomes, 2000, Vila Sacadura Cabral, Santo André, SP, Brazil, 09060870. rafaelsaleme@yahoo.com.br

Article received on 10/12/2020, approved on 10/26/2020. 
active movements in the intraoperative period ${ }^{1,3,5,6}$ with direct and immediate view of the correction of the lesion, if necessary. Finally, it brings less need for postoperative monitorization, ${ }^{2}$ discharging the patient 30 minutes after the end of the procedure, which reduces the length of stay in the postoperative care unit. ${ }^{2}$

In general, there is few restrictions for the use of this technique, being restrict only for patients with vascular insufficiency. ${ }^{5}$ The associated complications occur during the application, and the patient may report tremors, palpitations, and symptoms of agitation, which can last 26 about minutes, ${ }^{2}$ which is how long the medicine takes to reach the maximum vasoconstriction. In addition, it may occur a vasovagal reaction by applying with needle, which is easily reversed by placing the patient in Trendelemburg position. ${ }^{1,2}$ If necessary, it is possible to revert its adverse effects by applying the phentolamine antidote., ${ }^{1,2}$ This study aimed to report the know-how of the private and public health services concerning the WALANT procedure with regard to COVID-19 pandemic.

The hypothesis of the present study is that the WALANT anesthetic technique is efficient for anesthetize and does not generate pain in patients during the intraoperative period of hand surgery, corroborating to the possibility of evaluating the efficacy of surgery in active movement during the intraoperative period.

\section{METHODOLOGY}

A retrospective, multicenter longitudinal study of cases of orthopedic hand surgery subjected to the WALANT anesthetic procedure at Hospital A and Hospital B, during the COVID-19 pandemic in August, 2020. An objective analysis of the verbal numerical scale in the preoperative, intraoperative, and postoperative period, subjective analysis of the efficacy of surgical repair with active movement of the patient in the intraoperative period, and description of the adverse effect presented were performed. A total of 20 patients with a mean age of 37.52 years (21 to 68 years-old) were included. The inclusion criteria were patients subjected to carpal tunnel release, tenolysis, ganglion cyst removal, De Quervain's release, phalangeal fracture surgery, neurolysis, and tenorrhaphy. Five patients were excluded. The exclusion criteria were patients that did not sign the informed consent form or did not want to make their data available for the study. All patients in the study signed the informed consent form. The study was approved by the Research Ethics Committee. Statistical analysis was performed by review manager 5.4 (RevMan) Core Software for Cochrane Reviews.

\section{RESULTS}

The patients reported a mean pain intensity score of 6.6 , with a standard deviation (SD) of around 2.35, when assessing the results from the Verbal Numerical Rating Scale (VNRS). This variation occurred due to the variety of lesions presented by the patients. No patient reported pain during the surgical procedure when asked the VNRS, which resulted in a average of 0.0 for pain intensity with SD around 0.0. For plotting purposes, we adopted the standard deviation as 0.01 in order to impose little interference as possible on the results. Even with a variation of techniques for each specific case, we proved the effectiveness of the anesthesia in the intraoperative period and the active movement capacity during the intraoperative period for different pathologies.

In the postoperative period, the pain intensity mean reported by the patients was 2.5 in the VNRS with SD of around 2.91.

Explicit results were obtained in graphs 1, 2 and 3 when establishing relationships between the VNRS reported in pre- and postoperative period; intra- and postoperative period; and pre- and intraoperative period.

Between the preoperative and postoperative periods, there is a $95 \%$ confidence interval with a mean difference of 4.10 [(2.46; 5.74)], a general effect of 4.90, and statistical significance lower than 0.00001 . Between the preoperative and postoperative periods, there is a $95 \%$ confidence interval with a mean difference of -2.50 ([-3.78; -1.22]), a general effect of 3.84, and statistical significance lower than 0.0001 . Between the preoperative and postoperative periods, there is a $95 \%$ confidence interval with a mean difference of 6.60 [(5.57; 7.63)], a general effect of 12.56 and statistical significance lower than 0.0001 .

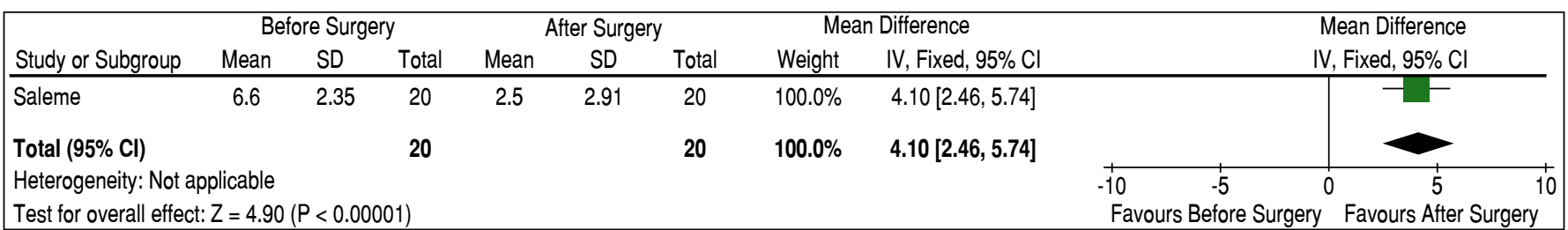

Graph 1. Assessment of pain: VNRS ratio between preoperative and postoperative of the sample.

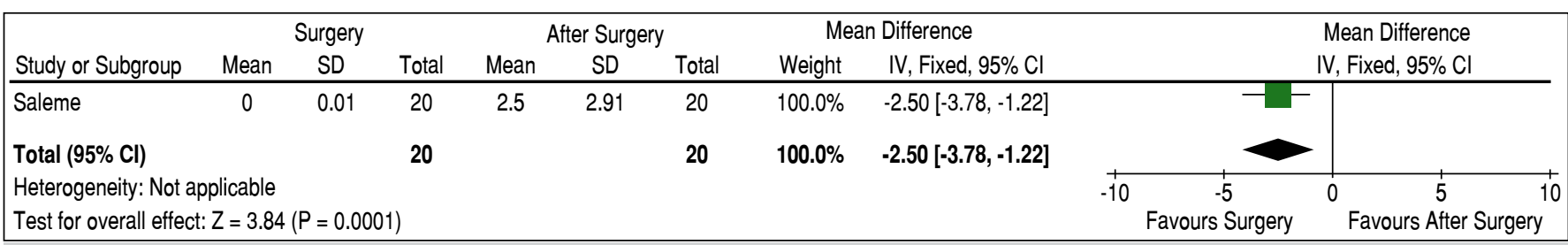

Graph 2. Assessment of pain: VNRS ratio between intraoperative and postoperative of the sample.

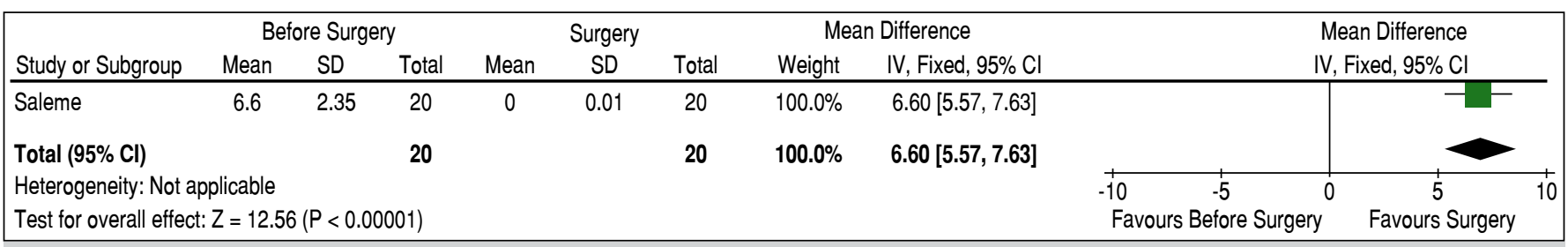

Graph 3. Assessment of pain: between preoperative and postoperative of the sample. 
The most common adverse reaction was palpitation in three patients, being resolved within five minutes after anesthetic application. Only one patient had a vasovagal reaction, which was quickly reversed with the Trendelemburg position.

\section{DISCUSSION}

With the COVID-19 pandemic and the need to perform hand and wrist surgeries with WALANT, since there is no sedation, ${ }^{2}$ it is possible to perform safe anesthesia without generating aerosol particles. Thus, the hand surgery team of the orthopedic services of the Hospital IFOR and the Hospital de Clínicas Radamés Nardini used the WALANT technique in cases that were convenient, since its applicability has resolution in up to $95 \%$ of cases of hand surgery. ${ }^{8}$ This local anesthetic technique provides lower-risk of viral dissemination because it does not have the need for ventilation. Moreover, it requires simpler operating rooms, ${ }^{4}$ minimum number of professionals, has lower material expenditure, and consequently lower hospital waste production. ${ }^{8}$

In urgent and emergency care services, hand traumatology surgeries require a quick resolution. For example, considering the tendon retractions, the sooner tenorrhaphy is performed, the lower the probability of fibrosis and tenolysis. ${ }^{4}$ As well as in cases of bone fracture, the sooner the osteosynthesis is performed, the lower the secondary damage to the patient. In order to support this point, Tang et al. ${ }^{3}$ state that in some cities in China, hand surgeons perform open fracture surgery, tenorrhaphies, and nerve repairs in emergency situations shortly after the patient's arrival, being an efficient system considering the anesthetic use of the WALANT technique, which facilitates trauma management and shortly surgical performance with less cost. Besides, Tang et al. ${ }^{3}$ state that hand surgeons and the department of anesthesiology have reached a consensus that local anesthesia is the main form of anesthesia for certain hand disorders and an anesthesiologist is not necessary in these cases, a well-trained orthopedic surgeon is sufficient, making the process more quickly to solve the trauma immediately.

Lalonde ${ }^{4}$ states that WALANT will soon be the gold standard anesthetic technique for tendon surgeries, as well as for hand, wrist and distal radius fractures. ${ }^{4}$ Also, the surgical approach with the wide-awake patient is the success for intraoperative evaluation of the repair, being able to correct and reduce complications in the surgery performance, thus generating greater surgical success. Corroborating the study discussed, the COVID-19 pandemic showed the needs of health services to adapt to the simplest and most advantageous anesthetic techniques. For the hand surgery team, the WALANT technique is the answer to surgical success with regard to the pandemic, also considering the benefits to the patient, post-surgical length of stay, and reduction of the consumption of hospital supplies.

\section{CONCLUSION}

That being said, both health services mentioned above used the WALANT anesthetic technique during the COVID-19 pandemic for the performance of necessary hand surgeries, and the difference lies in the anesthesia being applied by the own well-trained orthopedic surgeon. The patients subjected to this technique did not feel any pain during the surgery, proving it to be effective in its purpose. The possibility of evaluating the passive hand movement was a remarkable benefit, enabling greater surgical success and consequently less possibility of surgical re-approach, in addition to shorter post-surgical length of stay, thus, generating greater benefit to the patient's health.

The future perspective is that hand surgery services are able to implement this technique in their daily life due to its benefits.

AUTHORS' CONTRIBUTIONS: Each author contributed individually and significantly to the development of this article. RSA: conception or design of the study, data acquisition, writing and critical review of the content, active participation in the discussion of the results, review and approval of the final version of the study; DAPC: conception or design of the study, data acquisition, critical review of the content, active participation in the discussion of the results, approval of the final version of the study; PHOF: conception or design of the study, data acquisition, critical review of the content, active participation in the discussion of the results, approval of the final version of the study; SUS: conception or design of the study, critical review of the content, approval of the final version of the study; IMZ: conception or design of the study, analysis and interpretation of the data, writing and critical review of the content, active participation in the discussion of the results, review and approval of the final version of the study; SBS: conception or design of the study, analysis and interpretation of the data, writing and critical review of the content, active participation in the discussion of the results, review and approval of the final version of the study; MAS: conception or design of the study, analysis or interpretation of the data, writing or critical review of the content, active participation in the discussion of the results, review and approval of the final version of the study.

\section{REFERENCES}

1. Pires Neto PJ, Moreira LA, Las Casas PP. Is it safe to use local anesthesia with adrenaline in hand surgery? WALANT technique. Rev Bras Ortop. 2017;52(4):383-9.

2. Lalonde $\mathrm{DH}$. Minimally invasive anesthesia in wide awake hand surgery. Hand Clin. 2014;30(1):1-6.

3. Tang JB, Gong KT, Xing SG, Yi L, Xu JH. Wide-awake hand surgery in two centers in China: experience in Nantong and Tianjin with 12,000 patients. Hand Clin. 2019;35(1):7-12.

4. Lalonde $\mathrm{DH}$. Conceptual origins, current practice, and views of wide awake hand surgery. J Hand Surg Eur Vol. 2017;42(9):886-95

5. Gunasagaran J, Sean ES, Shivdas S, Amir S, Ahmad TS. Perceived comfort during minor hand surgeries with wide awake local anaesthesia no tourniquet (WALANT) versus local anaesthesia (LA)/tourniquet. J Orthop Surg (Hong Kong). 2017;25(3):2309499017739499.

6. Lalonde $\mathrm{DH}$. Latest advances in wide awake hand surgery. Hand Clin. 2019;35(1):1-6.

7. Lee DC. Wide awake hand surgery. Arch Plast Surg. 2017;44(4):348

8. Sardenberg T, Ribak S, Colenci R, Campos RB, Varanda D, Cortopassi AC. 488 cirurgias da mão com anestesia local com epinefrina, sem torniquete, sem sedação e sem anestesista. Rev Bras Ortop. 2018;53(3):281-6. 